\title{
THE HOUSE OF BETHEL AND CONSUMER-RUN BUSINESSES: AN INNOVATIVE APPROACH TO PSYCHIATRIC REHABILITATION
}

\author{
MARIKO KIMURA, \\ Japan Women's University, Kawasaki \\ IKUYOSHI MUKAIYACHI, \\ Health Science University of Hokkaido, Ishikari-gun, Hokkaido \\ and \\ ERIKO ITO \\ Urakawa Red Cross Hospital, Urakawa, Hokkaido
}

\begin{abstract}
This article reports on a psychosocial rehabilitation approach which is used by Bethel House in Urakawa, a town in the Hidaka district of northern Japan. This approach is unique in that its primary focus is community development, as opposed to therapeutic work. By starting its own businesses, the Bethel community has: (a) created many employment opportunities for people with mental illness and for members of the larger community; (b) brought about important changes in the attitudes of members of the community, and the hospital staff, towards the mentally ill; (c) improved the relationships among members of Bethel and the Urakawa community; and (d) significantly enhanced the town economy. Bethel success clearly illustrates a broader potential for creative approaches to psychosocial rehabilitation and community development.
\end{abstract}

\section{INTRODUCTION}

Ideally, psychiatric rehabilitation and community development should progress in tandem, like two wheels on a bicycle. When they do, they bring about many changes in the community-for people with psychiatric illnessess and for the community as a whole. Carling (1995) promotes such co-operative progress with the concept of "community integration," which is dependent upon the inclusion of people who traditionally have been labelled as different. Community integration also requires, according to Carling, a fundamental shift in the way that the traditional mental health system "does business." Such a shift must focus on the goal of community integration without losing sight of the reality of relapses, and must ensure the creation of a community wherein high-quality support is available to people with psychiatric illnesses.

With the progress of the consumer movement and consumer involvement in the planning process of mental health services, public funding has become available for consumer initiatives which not only enable people with psychiatric illnesses to become part of the working community but also empower them to participate in, and help with, their recovery processes (Anthony, 2000). In some provinces in 
Canada, consumer groups are funded to develop alternative kinds of support for mental health consumers (LeCount, 2000; Niles, 2001; Trainor, Shepherd, Boydell, Leffe, \& Crawford, 1997). Included among these initiatives are support groups, consumer-run businesses, and drop-in centres (Carling, 1995). Not only are these support models economically effective (by reducing the frequency of hospitalization or visits to physicians), but they also help consumers to develop their own social support networks (which, in turn, enables them to reduce the levels of formal care which they receive). Consumers with strong community support often are better able to put the focus of their lives in work, education, helping other consumers, and other meaningful ways of living (Coberstain, 2000; LeCount, 2000; Trainor, et al., 1997).

Finding employment for people with psychiatric disabilities is a wellestablished field. Anthony and Jansen (1984), in discussing issues of work performance, argue that there is no correlation between symptoms and functional skills; rather, they conclude that the best demographic predictors of work success are prior work history and an ability to "get along" and interact socially. The best psychological predictors of vocational performance are the levels of a person's ego strength or self-esteem. Aside from providing ongoing support to mental health consumers and serving as a bridge between them and their workplaces, the greatest challenge facing rehabilitation professionals is cultivating enough energy and personnel to develop relationships with longstanding local businesses with family-like atmospheres (PACT vocational counsellor, 2001).

In Japan, the work of employment rehabilitation for mental health consumers remains a struggle, largely because of various policy restrictions and limited funding and personnel. However, one Japanese psychosocial rehabilitation approach has been particularly successful. With its unique focus on helping consumers start their own businesses with the primary motivation of helping the town's economy rather than of providing themselves with theraputic gains, the Bethel initative has created many employment opportunities and has brought about significant change-for the mental health consumers who are its members, for the local hospital staff, and for the community in which it is situated.

\section{THE BETHEL INITIATIVE}

\section{Bethel House}

The town of Urakawa, with a population of 16,000 , is located near Cape Erimo on the Pacific coast of the Hidaka district of Hokkaido (a geographic area twice the size of Tokyo which is home to about 80,000 people). Since the climate of the region is wet and cold, the area is not suitable for agricultural farming. As a result, the town's economy traditionally has been supported by two activities: (a) the harvesting and sale of a marine product, Hidaka kelp, which is an indispensable item for Japanese cuisine; and (b) the raising of racehorses. However, by the late 1970s, the marine resources were exhausted and the horse-raising business had become unstable and, consequently, town had become depopulated (Mukaiyachi, 1999).

The town is served by the Urakawa Red Cross Hospital-a general hospital with 417 beds including 140 beds in the psychiatric ward (Mukaiyachi, 1999). In 
1978, the hospital hired the region's first social worker, Ikuyoshi Mukaiyachi, to support the psychiatric patients. At that time, the hospital's rules for psychiatric patients were rather rigid: patients in the open ward needed hospital permission three days in advance to leave the hospital, even just to go to a nearby store to fetch something. Discharged patients presented even more of a problem: those who were homeless and alcoholic were hanging around at the hospital lobby drinking and sleeping, because there were no alternative places to go to escape the severe cold weather; those who were receiving public assistance lived in old terrace houses or old apartments near the hospital. Some of these former psychiatric patients caused problems with their neighbours, and the local police took to driving back and forth, re-committing the patients to the psychiatric wards. As a result, the Urakawa community, as a whole, held strong negative opinions about the mentally ill (Mukaiyachi, 1999).

Soon after Mukaiyachi came to work at the hospital, he formed the Acorn Club, a social club for psychiatric consumers-current in-patients, out-patients, and former patients (Mukaiyachi, 1999). An old church building near the hospital provided meeting space for the club as well as communal living space for some discharged patients. For the first few years of his stay in Urakawa, Mukaiyachi lived in the church building with some discharged patients. By 1984, patients regularly began moving into the space upon discharge.

Living together provided house members with a unique opportunity for mutual support. In an information video prepared by the members, one scene clearly depicts such support:

One member is suffering from delusions and is not able to concentrate on daily activities at the apartment. This member says, "I am not feeling well, and delusions are quite overwhelming." A friend comes and says to her, "I know how you must be feeling, but if you indulge yourself in your delusional state, your friends would not take interest in you. Try to look around, and try to switch your mind. We want you to be connected to the real world" (Bethel, 2000b).

In a collective living situation, members form a closely-knit support network, and they become aware of each other's physical and mental health conditions. Members intervene in each other's crises, and point out what works under delusional conditions. They try to use their own experience-based knowledge to support one another.

Eventually, the centre came to be named Bethel House. As the name implies, Bethel is closely related to the local church and church members. Some Bethel members also belong to the church. In the Bethel video, one member describes the church community as a place where he can blend in, and contribute in the same way as other church members. For many members, this spiritual and social connection is important.

\section{Kelp Buying, Processing, and Selling at a National Scale}

Bethel House soon came to be used as a community workshop. Former patients, who lived near the hospital, commuted daily to the house to work as subcontractors for a local factory, which needed dried kelp cut and packaged for home cooking. If there had been no trouble with that contract, Bethel might not have started its business. However, one day when the kelp being delivered to the centre 
from the factory was late arriving, a workshop member who was feeling delusional and angry phoned the factory director and yelled at him about the delay. The angry factory director appeared at the workshop, took the rest of the work away, and announced that it was the end of the business with Bethel. As a result, in 1988, the members of Bethel made a decision to start their own business.

The members knew that the local factory already had established markets, and that their endeavour would appear reckless to some. Nonetheless, they decided to open up outlets throughout the country to sell the kelp directly (Mukaiyachi, 1999). Members of Bethel had their own reasons for their decision: (a) it would be difficult for them to mend the relationship with the factory, and (b) they wanted to do something to contribute to and revive their community. They began by going to the local fishery trade union, talking about their plans, and asking for help to start their own business. The fishery union was helpful and co-operative. With seed money of 100,000 yen (approximately $\$ 12,000 \mathrm{CAD}$ ), Bethel was able to buy the kelp from the fishery union (Mukaiyachi, 1999) and to begin the work of buying, processing, packaging, selling, and advertising.

Bethel members made use of their church connection to begin selling their product. They began by attending the 1988 United Church General Assembly-which was held in Sapporo, the largest city in Hokkaido at the time-so that they could describe the centre and its work. The sales results from this first endeavour were reasonably promising and, with the help of the church women's groups and other women's groups throughout the country, word of Bethel's packaged kelp began to spread. By its seventh year, the direct sales of Bethel's kelp business reached 12 million yen a year and, since then, these sales have been contributing to the local economy.

Bethel made inroads into the local market because they were willing to help revive the local community: they planned to develop businesses which were underdeveloped in the area, to rebuild networks of people, to bring back people to work by creating new job markets, and to re-establish relationships between the people in the community and people with psychiatric illnesses.

\section{Personal Care Goods Delivery to the Elderly}

In June 1993, Bethel began a second business - the delivery of personal care goods, mainly to elderly persons in the community. By working at the general hospital, and learning how elderly people live in a depopulated community, Mukaiyachi had gained insights which helped him assess the needs and the marketability of these products. He recognized that many elderly persons in the community did not have family members who were able to act as caregivers, accompanying them to the hospital or to the shops. He also saw that the local shops were not willing to deliver personal care goods to the elderly except when they were ordered in large quantities. Bethel members began delivering single packages of disposable diapers to elderly persons at a general hospital ward or at their own homes in the community. This work resulted in two significant gains: (a) people in the community began to show respect to Bethel members, who were increasingly appreciated for undertaking this business and for their evident willingness to help others; and (b) a drastic attitudinal change occurred in the staff of the general ward of Urakawa Red Cross Hospital who, upon seeing Bethel members regularly delivering packages to 
hospitalized elderly patients, developed a more positive perspective on people with psychiatric illnesses.

\section{Bethel Shop}

Because of the work capacity problems - such as an inability to maintain physical or mental energy or concentration levels-which often are associated with psychiatric disabilities, traditional work situations were not appropriate for many Bethel members. Thus is was important for Bethel to create other work opportunities for its members. Accordingly, staff began approaching community members and local businesses to offer the services of Bethel members. The arrangements made by the staff better suited the needs of the members: work hours were kept short and members were encouraged to register the total number of hours they wanted to work and to design their own schedules.

Local businesses grew to appreciate Bethel's services, and the centre was asked to undertake work in an increasing number of new areas. Some local supermarkets, for example, asked Bethel members to come in and clean the floor a few hours a week-and Bethel members decided to take these and similar job offers. As they began participating in various kinds of work, Bethel's members assumed ownership of specific tasks (e.g., driving, cleaning) and, even though doing so meant changes to longstanding routines (such as not getting up early in the morning), they were able to adapt and to complete their contracts.

Given the success of these endeavours, and in light of a stable number of work orders from local businesses, Bethel decided to establish a company called "Bethel Shop." The shop was able to employ many of Bethel's members and some, who used to be social welfare recipients, were able to work enough hours so that they could be covered with employee's insurance and live independently of welfare. At present, Bethel members are engaged in various contract jobs, including maintaining parks, handling daily necessities such as household items, managing 11 apartment buildings, washing dishes and delivering meals for the hospital, publishing, training mental health professionals, and working in the travel industry. With the variety of jobs Bethel has developed, more than 90 people are now employed (both Bethel members and members from the community at large) in a business with an annual total sales of 70 million yen.

As Bethel's reputation grew among local businesses and word-of-mouth referrals increased, the centre was approached by a number of shop-owners with offers of contract work. By focusing on underdeveloped employment areas, the centre was able to attract many potential customers. Generally, Bethel took on whatever jobs came its way, and viewed each new opportunity as a challenge. By taking on more jobs, it was possible for more members to be encouraged to work. These experiences have led Mukaiyachi to believe that helping the psychiatrically disabled to return to the community requires more than traditional psychiatric rehabilitation-it requires regaining the trust of the community, a trust which can only be built by improving communication among community members.

Bethel's approach has been well received by the community. Members have a gentle way of dealing with clients who live at home with disabilities. They are patient with them and are able to successfully help them with a variety of needs. In turn, they have learned some things about themselves: despite having been led to 
believe that they were unable to care for themselves because of their illnesses, Bethel members have developed confidence, have begun working on their own personal care (e.g., self-grooming), and have started taking pride in their well-earned reputation.

\section{An Alternate Model of Work}

The levels of work that the Bethel members are engaged in vary. Some are entry level, some intermediate, and some require more advanced skills. Some members had prior work experience before the onset of their illnesses (such as working as a mechanic or in a bank); others have minimal education and experience. However, since Bethel runs the company and deals with the whole process of the business (from accounting to fixing wheelchairs to driving to packaging kelp), it is possible to accommodate these different interests and skill levels.

"At Bethel, staff and members share information and troubles," says Mukaiyachi (Bethel, 2000a), which means members are in charge of their own symptoms and health conditions and the consequences of the decisions they make. Bethel currently owns various kinds of businesses and a workshop, and many members are working daily. Every morning, when members come to work, they are expected to report their condition on that day and to decide for themselves how many hours they will be able to work during the day.

When members try new jobs, says Muraiyachi, "it is important for them to expect what's coming at a new working environment. When they feel defeated or that the job is not going well, or [are] feeling that the day is not successful, they take it as a natural consequence [of their inabilities]. When trying something new, it could be stressful, and it should get better as it goes. It is normal to feel stressed" (Bethel, 2000b).

Bethel's way of working and dealing with psychiatric disabilities is flexible. For the contract jobs, members share the total working hours and work to fill the space when a regular member is unable to meet the commitment. If necessary, Bethel's staff will work to fill an absence. Staff and experienced members also help to coach other members. One member, for example, who often cannot work for a complete hour, is good at finding a substitute to help make up the time. Mukaiyachi stresses the importance of this kind of self-knowledge and responsibility: members should not be excluded from work because of their needs; they simply have to know how to accommodate them appropriately. ibility:

A scene in Bethel's information video highlights the importance of this flex-

Bethel members can be seen working alongside in-patients in the hospital garden, which had been donated by the Japanese Horse Owners' Association, while Dr. Kawamura, chief psychiatrist of Urakawa Red Cross Hospital, says "you might notice that some people are not doing anything, and it is important. People work hard when somebody is watching. There is a purpose for some members not working. At Bethel, it is completely acceptable to have people not doing anything at various psychosocial programs. People who are capable and are willing to do things on their own could appreciate their own conditions, and come to accept others the way they are. Some members who are not as energized as others know what they want to do next by looking at other members' actions" (Bethel, 2000a). 


\section{Community Education}

The members of the Bethel community believe that it is important to share their experiences not only within the northern community of Urakawa, but also throughout the country. Admitting to mental illness is still not "done" in Japan, so any sharing that the members do choose to undertake involves an element of risk. Nonetheless, community education remains an essential component of the Bethel initiative.

To aid in that education process, Bethel members have collaborated with the hospital and with Niigata Spring Film Productions to create a series of videos, entitled "Very Ordinary People." Each video-with titles such as "What is ordinary," "Starting our own business," or "Company with a notion that employees feel at ease to say they need to take a break" - explores various aspects of the members' lives. These videos are promoted and sold by Bethel members, who have even made appearances on national network television news. They are widely used for mental health courses at social work schools throughout the country.

To further promote community education about mental illness, the members of Bethel have created the "Hearing Voices Contest," which is held annually. Building upon the hearing voices movement, which is a growing world-wide movement of support groups for people with psychiatric illness, Bethel members hold a "delusion and auditory hallucination contest" in which members who are suffering from auditory hallucinations and delusions talk about their experiences and receive prizes for the year's most extraordinary hallucinations. The benefits of this contest are twofold: (a) Bethel members are able to release their sufferings and accept their symptoms, and (b) hospital staff and community members gain greater recognition and acceptance of the experiences of the contestants.

\section{CONCLUSIONS: LEARNING FROM BETHEL}

Bethel's practices have been derived from its own experiences rather than from a "borrowed knowledge" of psychosocial rehabilitation in North America. Nonetheless, they are effective not only as a means of supporting their own members and the small community of Urakawa, but also as a means of illustrating how psychosocial rehabilitation can be creative, and need not be undertaken within a therapeutic setting.

The prospect of starting their own business and earning their own money was a primary factor in motivating Bethel's members to succeed in this rehabilitation process. Even though people with mental illnesses traditionally have been deprived of such opportunities, Bethel members discovered that the business world held the potential to engage them in "real world" daily activities (Mukaiyachi, 2002). This potential could be realized, they learned, if the business community was willing to accommodate their expectations, so that the needs of both the companies and the workers could be met. Because the community of Urakawa was willing and able to accept this need, Bethel members have been able to affirm themselves as community members and as workers.

A second factor in the success of the Bethel program was the mutuality of the relationship between the members and the Urakawa community. In a traditional mental health service relationship, the roles are very clear: clients are the service 
recipients; professionals are the service providers. In the Bethel experience, these roles changed. Since the primary goal of the program was community revitalization, it was crucial that the Urakawa community and the Bethel members work collaboratively-and Bethel's businesses provided the context in which the collaborative relationship could emerge. As Mukaiyachi observes, it is not possible for psychiatric rehabilitation to be separated from a community system and still be effective. If psychiatric rehabilitation tries only to encourage the independence of the psychiatrically disabled, it will not work (Mukaiyachi, 1999). Bethel's approach was to work toward rebuilding the local community for all of the community-those people with and without psychiatric illnesses.

Another important factor in the program's success was the process of community education. As Mukaiyachi notes, the vulnerability experienced by all human beings tend to be expressed more clearly by people with psychiatric illnesses because the difficulties of living tend to be manifested where the weaknesses are concentrated. Bethel was able to re-establish a healthy relationship with the broader community by gaining, and sharing, insights into the similiar vulnerabilities of the local population and people with psychiatric illnesses. "Unless local communities learn from each other and make the most of the experience," Mukaiyachi writes, "they would not make a further development in Urakawa. Bethel is the 'epitomy' of the Urakawa community" $(1999,147)$.

Finally, the innovation and ongoing commitment of professionals were essential to Bethel's success. Neither Ikuyoshi Mukaiyachi (the social worker who initiated the project) nor Dr. Kawamura (the chief psychiatrist at Urakawa Red Cross Hospital) came to the small town of Urakawa with the intention of staying for a long time. However, both men became engaged by the project and developed a strong working partnership. Together they encouraged Bethel members to develop their own skills, form social relationships, take control of their lives, and take risks. By providing the members with professional back-up and community support, and by facilitating the relationship between Bethel and the hospital and business communities, Mukaiyachi and Kawamura encouraged a philosophy of psychosocial rehabilitation which encouraged members to stand on their own feet.

The Bethel initative has been based on this psychosocial rehabilitation philosophy. As a process of empowerment to help patients gain personal, interpersonal, social, financial, and political power, it supports individuals, families, groups, and the broader community so that they can have a stronger influence on improvements within their own environment (Germain, 1979).

\section{RÉSUMÉ}

Dans cet article, nous présentons une méthode de réadaptation psychosociale utilisée par la maison Bethel Urakawa, une ville du district de Hidaka au nord du Japon. Il s'agit d'une démarche unique qui privilégie le développement communautaire et non la thérapeutique comme telle. En démarrant ses propres entreprises, la communauté de Bethel a réalisé les fins suivantes: (a) la création de plusieurs opportunités de travail tant pour les personnes souffrant de maladie mentale que pour les membres de la communauté en entier; (b) la transformation des attitudes des membres de la communauté y compris le personnel des services hospitaliers, l'égard des personnes malades mentales; (c) l'amélioration des relations entre les membres de Bethel et la communauté d'Urakawa; 


\section{THE HOUSE OF BETHEL AND CONSUMER-RUN BUSINESSES}

(d) des changements importants dans l'économie de la ville. Le succès de Bethel donne un exemple frappant de ce que peut accomplir les approches innovatrices dans la réadaptation psychosociale et le développement communautaire

\section{REFERENCES}

Anthony, W.A., \& Jansen, M.A. (1984). Predicting the vocational capacity of the chronically mentally ill: Research and policy implications. American Psychologist, 39, 537-548.

Anthony, W.A. (2000). A recovery-oriented service system: Setting some system level standards. Psychiatric Rehabiliation 24, 159-168.

Carling, P.J. (1995). Return to community: Building support systems for people with psychiatric disabilities. New York: Gilford.

Germain, C.B. (1979). Social work practice: People and environment, and ecological perspective. New York: Columbia University Press.

LeCount, D. (2000). Keeping the treatment focus in community: Madison Model. Presentation to the Japanese Psychiatric Rehabilitation Conference in Obihiro.

Mukaiyachi, I. (1999). The House of Bethel in Urakawa and the role of social workers: Twenty-one years of experience putting emphasis on the social contribution of people with psychiatric illness. Japanese Current Psychiatry, 4(2), 145-151.

Bethel's Video, Ordinary people 6. (2002a). Urakawa, Japan: Niigata Spring Film Production Co. Ltd. (In Japanese, available through Bethel.)

Bethel's Video. Ordinary people 4. (2002b). Urakawa, Japan: Niigata Spring Film Production Co. Ltd. (In Japanese, available through Bethel.)

Trainor, J., Shepherd, M., Boydell, K.M., Leffe, A., \& Crawford, E. (1997). Beyond the service paradigm: The impact and implications of Consumer/Survivor Initiatives. Psychiatric Rehabilitation Journal, 21(2), 132-140. 